\title{
Application of a bacteriological on-farm test to reduce antimicrobial usage in dairy cows with purulent vaginal discharge
}

\author{
L. V. Madoz, ${ }^{*} \dagger^{1}$ I. Prunner, $\ddagger^{1}$ M. Jaureguiberry, ${ }^{*} \dagger$ C.-C. Gelfert, $§$ R. L. de la Sota, ${ }^{*} \dagger$ M. J. Giuliodori,\# \\ and M. Drillich $\ddagger^{2}$ \\ ${ }^{*}$ Cátedra y Servicio de Reproducción Animal, Facultad de Ciencias Veterinarias, Universidad de La Plata (FCV-UNLP), La Plata, B1900AVW, \\ Argentina \\ †Consejo Nacional de Investigaciones Científicas y Técnicas (CONICET), Buenos Aires, C1033AAJ, Argentina \\ łUniversity Clinic for Ruminants, Clinical Unit for Herd Health Management in Ruminants, University of Veterinary Medicine Vienna, 1210 Vienna, \\ Austria \\ §MSD Animal Health, 85716, Unterschleißheim, Germany \\ \#Cátedra de Fisiología, FCV-UNLP, La Plata, B1900AVW, Argentina
}

\begin{abstract}
The objective of this study was to assess the effect of a selective antibiotic treatment strategy based on a quick bacteriological on-farm test (Petrifilm, 3M Corp., St. Paul, MN) compared with the conventional antibiotic treatment of all cows having clinical endometritis $(\mathrm{CE})$ defined by the presence of purulent vaginal discharge on both clinical cure rate and reproductive performance. The study was simultaneously conducted with dairy cows reared under a highly supplemented rotational grazing system in Argentina and in a freestall system in Slovakia. Cows having an abnormal vaginal discharge (VD, indicative of clinical endometritis) on 21 to $35 \mathrm{~d}$ in milk (DIM) were randomly allocated to 1 of 2 study groups: selective treatment (ST) or conventional treatment $(\mathrm{CT})$. All cows in the $\mathrm{CT}$ group (n $=174$ ) received a single intrauterine administration of $500 \mathrm{mg}$ of cephapirin. In the ST group $(\mathrm{n}=178)$, treatment decision was made according to the results of the bacteriological on-farm test. For this test, we collected intrauterine samples with the cytobrush technique and stroke the brushes onto 2 different Petrifilm plates, one for aerobic count and another for Enterobacteriaceae count, incubated the plates, and counted the number of colonies after $24 \mathrm{~h}$. Positive cows $(\geq 5$ colonies in one or both plates) received a single intrauterine treatment with $500 \mathrm{mg}$ of cephapirin, whereas negative cows $(<5$ colonies $)$ remained untreated. Clinical cure rate was assessed by direct vaginal inspection at $14 \mathrm{~d}$ after treatment (VD-0). The odds for conception at first artificial insemination, artificial insemination by 80
\end{abstract}

\footnotetext{
Received August 29, 2016.

Accepted January 9, 2017.

${ }^{1}$ These authors contributed equally to this work.

${ }^{2}$ Corresponding author: marc.drillich@vetmeduni.ac.at
}

DIM, pregnancy by 100 DIM, and for nonpregnancy by 200 DIM were estimated with mixed logistic regression models. The hazard of conception was also assessed with proportional hazard regression model. The selective antibiotic treatment strategy based on the outcome of Petrifilm test reduced the number of required treatments $(57 \%)$ and maintained similar efficacy in terms of clinical cure and reproductive performance as the conventional antibiotic treatment of all endometritic cows.

Key words: clinical endometritis, purulent vaginal discharge, bacteria, antibiotic treatment, Petrifilm

\section{INTRODUCTION}

Clinical endometritis (CE) is commonly defined as an endometrial inflammation with the presence of purulent or mucopurulent vaginal discharge (VD) without systemic signs of illness in cows with more than 20 DIM (Sheldon et al., 2006). Some cows with abnormal VD have no cytological evidence of endometritis, and therefore the term "purulent vaginal discharge" (PVD) can be used instead of CE (Denis-Robichaud and Dubuc, 2015b; Dubuc et al., 2010). Clinical endometritis or PVD affects 15 to $20 \%$ of cows at 4 to 6 wk postpartum and impairs fertility, consequently worsening the economic situation of farms (LeBlanc, 2008). Beside prevention strategies, treatment of $\mathrm{CE}$ is a topic of controversial discussion (Dubuc et al., 2011). This controversy is triggered by high self-cure rates ranging from 63 to $77 \%$ (Gautam et al., 2010; Dubuc et al., 2011; Plöntzke et al., 2011; Giuliodori et al., 2013) and by the unsatisfactory results of some treatment regimens. For example, the use of proteolytic enzymes is not recommended (Drillich et al., 2005), homeopathic remedies were not effective (Arlt et al., 2009), and local treatment with dextrose yielded inconsistent results 
(Brick et al., 2012; Machado et al., 2015; Maquivar et al., 2015). In addition, conflicting reports exist on the use of prostaglandin $\mathrm{F}_{2 \alpha}$ with regard to cure rate and reproductive performance (Mejía and Lacau-Mengido, 2005; Hirsbrunner et al., 2006; Kaufmann et al., 2010; Dubuc et al., 2011; Haimerl et al., 2013). However, the efficacy of an intrauterine antibiotic therapy with cephapirin has been demonstrated in several studies (LeBlanc et al., 2002; Runciman et al., 2009; DenisRobichaud and Dubuc, 2015a). Cephapirin, a firstgeneration cephalosporin, is approved for the treatment of bovine endometritis in many countries, but not in the United States. In general, the use of antibiotics in food-producing animals, particularly highly critical important antibiotics ("reserve antibiotic") in human medicine (e.g., third- and fourth-generation cephalosporins), should be kept to a minimum. In this sense, for example, the European Union is funding programs to assess the amount of antibiotics used and their resistance rates (directive 2003/99/EC). In Latin America, the first regulations have recently been released in Argentina (directives 834/2015 and 391/2015) with the intent of assessing antibiotic usage and bacterial resistance in food-producing animals. Because the use of antimicrobials in food animals is considered to lead to the development of resistance to these drugs (Santos et al., 2010; Kasimanickam et al., 2016), an urgent need exists for new treatment strategies (e.g., selected treatment strategies). Detailed clinical examination, the assessment of animal-based welfare parameters, and the use of predictive laboratory tests have been suggested as relevant measures to improve the situation on farm (Trevisi et al., 2014). Thus, the challenge for practitioners is how they can reduce the amount of antibiotics to a minimum by implementing a preventive management program at the herd level to control the proportion of cows with $\mathrm{CE}$ and then to treat them efficaciously to maintain their fertility.

Petrifilm (3M Corp., St. Paul, MN) was originally developed for on-site determination of bacteria in drinking water, food products, and other items (Bredie and de Boer, 1992; Schraft and Watterworth, 2005). Recently, the use of Petrifilm as a rapid on-farm test for detection of mastitis pathogens in dairy cows was shown to enable implementation of a selected and targeted mastitis treatment strategy (McCarron et al., 2009; Cameron et al., 2014). Therefore, our hypothesis was that the use of this rapid on-farm bacteriological test could help us to select cows with PVD for antibiotic treatment and thus reduce the number antibiotic treatments in dairy cows. Our objective was to assess the effect of a strategy that is based on the use of the on-farm test followed by selected treatment of positively identified cows (selective antibiotic treatment) compared with conventional treatment of all cows with PVD on both clinical cure rate and reproductive performance.

\section{MATERIALS AND METHODS}

\section{Study Design}

This study was simultaneously conducted on dairy farms in Argentina and Slovakia as a completely randomized block design with country as the blocking criterion and cow as the experimental unit. Sample size was estimated with a confidence level of $95 \%$ and a power of $80 \%$. We assumed cure rates of $50 \%$ and $65 \%$ for selective and conventional groups, respectively. The estimated sample size was 133 cases per group or approximately 266 cows to be enrolled in the trial. A onesided significance level was used because no negative effect of treatment was expected. This estimation was run with the option Sample size/Estimate differences between percentages in WinEpi (http://www.winepi. net/uk/index.htm). Cows included were postpartum dairy cows (21-35 DIM) having VD $\geq 1$ (abnormal vaginal discharges) and not having cesarean section, fetotomy, or systemic antibiotic treatment after parturition (to avoid false-negative bacteriological findings). From a total of 352 enrolled cows, 152 belonged to the Argentinean farm (78 primiparous and 74 multiparous cows) and 200 to the Slovakian farm (all multiparous cows).

\section{Study Farms and Herd Management}

The Argentinian part of the study was conducted on a commercial dairy farm with 2,600 Holstein Friesian cows, located in Carlos Casares $\left(35^{\circ} 37^{\prime} \mathrm{S}, 61^{\circ} 22^{\prime} \mathrm{W}\right)$, between November 2013 and August 2015. The land base of the dairy farms was 2,000 ha. Prepartum transition cows that were within 4 wk of expected calving date were maintained on dry lots, fed a low DCAD diet, and monitored for signs of calving by farm employees trained to assist parturition. After calving, cows were sent for $3 \mathrm{~d}$ to the fresh herd and kept on a dry lot. Lactating cows were at pasture in a rotational system (different paddock in the morning and afternoon). Feed was composed of mixed pastures (lucerne, tall fescue) and winter annual grasses (ryegrass) and supplemented with TMR diets (corn silage, soybean pellets, and corn meal) formulated to meet or exceed the NRC (2001) nutrient requirements for lactating Holstein cows weighing $650 \mathrm{~kg}$ and producing $45 \mathrm{~kg}$ of milk $(3.5 \%$ fat). Concentrates (40\% soybean pellets and $60 \%$ corn meal) were offered twice daily during milking. Average milk yield was $9,600 \mathrm{~kg}$ per lactation. Calving occurred year round except for the hot summer months (January 
and February). Farm veterinarians visited the farms routinely every second week for reproductive examination. After a voluntary waiting period of $50 \mathrm{~d}$, cows were detected for estrus twice daily and artificially inseminated with the a.m.--p.m. rule. Estrus detection was facilitated by tail painting. Cows were considered in estrus when over $50 \%$ of tail paint was removed. Ovsynch protocol was used for cows not bred within 70 DIM. Pregnancy was diagnosed by ultrasound between 30 and $45 \mathrm{~d}$ post insemination. Pregnant cows were rechecked by ultrasound at $150 \mathrm{~d}$ of gestation. Relevant data were managed with herd management software Protambo Master 3.0 (DIRSA SA, Buenos Aires, Argentina).

The European part of the study was conducted on a commercial dairy farm with 2,600 Holstein Friesian cows in the region of Záhorie, Slovakia, between August 2013 and February 2015. Cows were housed in freestall facilities with cubicles and concrete floors. Feeding was based on a TMR consisting of wheat straw, corn silage, lucerne silage, beet pulp silage, concentrates, soybean meal, and corn grain as the main components. Cows were milked 3 times daily and the herd average milk yield was $9,000 \mathrm{~kg}$ per lactation. Before parturition cows were brought to a straw-bedded group calving pen. Calving occurred all year round. The voluntary waiting period was set at 50 DIM. Cows were bred by AI after observed estrus. Ovsynch protocol was used for cows not bred within 70 DIM. Pregnancy diagnosis was performed after $35 \mathrm{~d}$ post insemination by manual transrectal palpation and ultrasonography of the uterus and its contents by local veterinarians. Pregnant cows were rechecked by transrectal palpation at $150 \mathrm{~d}$ of gestation. Relevant data were managed with herd management software DairyComp 305 (Valley Agricultural Software, Tulare, Canada).

\section{Clinical Examination and Sampling}

All dairy cows were examined between 21 to 35 DIM by manual vaginal inspection with a gloved hand (Pleticha et al., 2009) and transrectal palpation. Vaginal discharge was assessed with the following score: VD-0 (normal clear discharge), VD-1 (clear discharge with pus flecks), VD-2 (mucopurulent not fetid discharge), and VD-3 (watery, purulent or brown-colored, and fetid). The BCS of cows was assessed on a 5-point scale (Edmonson et al., 1989), and cows were tail bled to determine BHB concentration in whole blood (FreeStyle Precision; Abbott Germany, Wiesbaden, Germany). After clinical examination, intrauterine samples were collected using the cytobrush technique as described earlier (Kasimanickam et al., 2004; Prunner et al., 2014). The cytobrush (Gynobrush, Heinz Herenz,
Hamburg, Germany; $20 \mathrm{~mm}$ in length and $7 \mathrm{~mm}$ in diameter), screwed on a metal rod and protected by a disposable plastic catheter and a plastic sheath, was inserted into the uterine cavity similar to AI technique. Inside the uterine cavity, the sheath was drawn back and the brush was moved forward and rolled onto the endometrial wall. We sampled every cow twice to obtain one specimen for bacteriological testing and the second for cytological examination. The first brush was washed out in $3 \mathrm{~mL}$ of lysogenic broth medium, and $1 \mathrm{~mL}$ of the fluid was subsequently placed in each of the 2 different Petrifilm plates, one for aerobic count and another for Enterobacteriaceae count (3M Corp.), which were then incubated at $37^{\circ} \mathrm{C}$. The Petrifilm plates were inspected after $24 \mathrm{~h}$ of incubation, and the number of grown colonies was counted. From 88 randomly selected animals, a routine bacteriological analysis was performed to obtain information about the population of present bacteria (Westermann et al., 2010). The second cytobrush was used to determine the proportion of PMNL in the endometrial sample. A total of 200 cells were counted under a microscope by $400 \times$ magnification to determine the proportion of PMNL (Melcher et al., 2014). A proportion of 5\% PMNL was chosen as the threshold for endometritis (endometrial inflammation). These findings were used to determine the proportion of false-positive findings for endometritis by vaginal examination (VD-1 to VD-3) in both groups (Westermann et al., 2010).

\section{Animal Treatment}

Cows with even ear tag numbers were allocated to the selective treatment (ST) group and cows having odd ear tag numbers were allocated to the conventional treatment (CT) group. Animals in the ST group were treated according to the readout on the Petrifilm plates after $24 \mathrm{~h}$ of incubation. Each sample was categorized as positive if $\geq 5$ colonies were counted on one or both plates. Positive cows received a single intrauterine treatment with $500 \mathrm{mg}$ of cephapirin (Metricure, Intervet, Boxmeer, the Netherlands) according to the manufacturer's instructions, whereas negative cows $(<5$ colonies on one or both plates) remained untreated. All cows in the CT group received a single intrauterine administration of $500 \mathrm{mg}$ of cephapirin, independent of the results of the cytobrush (Figure 1). Authors or the farm veterinarians applied the intrauterine treatments. Clinical cure was assessed by manual vaginal inspection at $14 \mathrm{~d}$ after treatment by the authors or by the farm veterinarians. Clinical cure was defined as VD-0. Reproductive performance was assessed by the odds for conception at first artificial insemination (CR1AI), artificial insemination by 80 DIM (AI80), pregnancy 


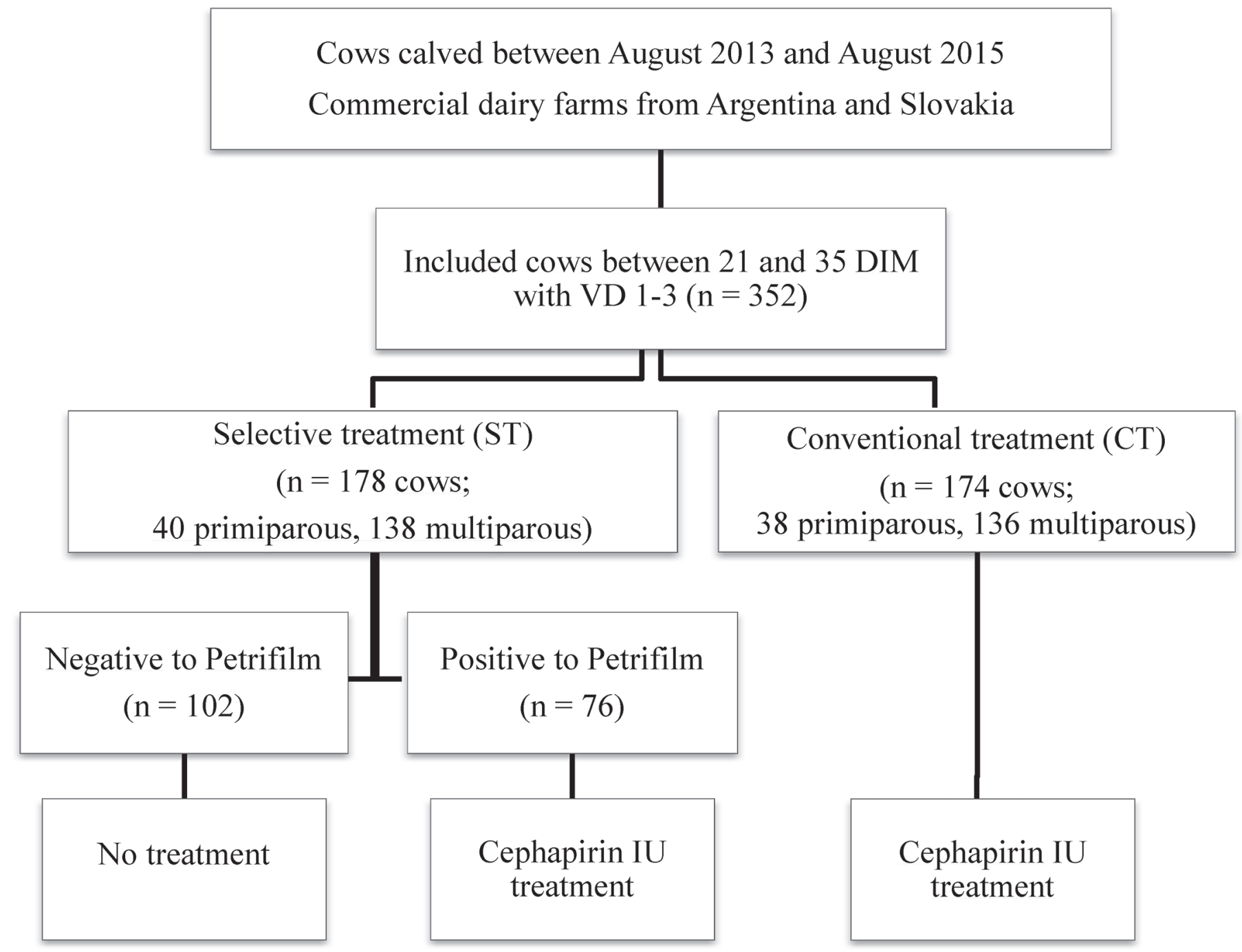

Figure 1. Flowchart showing study design and treatment allocation. VD 1-3= vaginal discharge with a score of 1 to 3 . Petrifilm (3M Corp., St. Paul, MN).

by 100 DIM (P100), and nonpregnancy by 200 DIM (NP200) and also by the hazard of conception.

\section{Data Management and Statistical Methods}

Results from clinical examinations were recorded on case report forms and transferred into spreadsheet software (Excel 2010, Microsoft Office Corporation, Redmond, WA). The statistical analyses were performed with SAS (version 9.2; SAS Institute Inc., Cary, NC). Animal data included parity, date of parturition, BCS, BHB concentration, VD, results from cytological and bacteriological examination, and reproductive performance. Mixed logistic regression models were used to assess the effect of treatment strategy on clini- cal cure rate, CR1AI, AI80, P100, and NP200. These logistic models included the random effect of farm and the fixed effect of parity ( 1 vs. $\geq 2$ ), VD at enrollment (1 vs. 2 vs. 3 ), treatment strategy (CT vs. ST), and second-order interactions. Models were also controlled for the fixed effect of cytological examination $(<5 \%$ vs. $\geq 5 \%$ PMNL), daily milk production (every $5 \mathrm{~kg}$ ), BCS (every 0.25 unit), and BHB (every $0.1 \mathrm{mmol} / \mathrm{L}$ ) as continuous predictors. Modeling was performed by backward removal of predictors with a $P>0.1$ (except for the effect of treatment that was forced to remain in models). The Cox proportional hazard regression models included the same fixed effects as the logistic models and the effect of country under the strata option. Modeling was also performed as previously described 
Table 1. Clinical cure rate and reproductive performance of cows with purulent vaginal discharge in a selective antimicrobial treatment strategy compared with conventional treatment strategy

\begin{tabular}{|c|c|c|c|c|c|}
\hline Group & $\%$ & No./total & $\mathrm{AOR}^{1}$ & $95 \%$ CI & $P$-value \\
\hline Conventional $^{3}$ & 60.34 & $105 / 174$ & 1 & & \\
\hline Conventional $^{3}$ & 24.07 & $39 / 162$ & 1 & & \\
\hline Selective $^{4}$ & 24.68 & $39 / 158$ & 1.171 & $0.692-1.984$ & 0.555 \\
\hline \multicolumn{6}{|l|}{ AI by 80 DIM } \\
\hline \multicolumn{6}{|c|}{ Pregnancy by 100 DIM } \\
\hline Conventional $^{3}$ & 29.75 & $47 / 158$ & 1 & & \\
\hline Selective $^{4}$ & 32.03 & $49 / 153$ & 1.142 & $0.692-1.884$ & 0.603 \\
\hline \multicolumn{6}{|c|}{ Nonpregnancy by 200 DIM } \\
\hline Conventional $^{3}$ & 18.98 & $26 / 137$ & 1 & & \\
\hline Selective $^{4}$ & 20.97 & $26 / 124$ & 1.113 & $0.615-2.014$ & 0.724 \\
\hline \multicolumn{6}{|c|}{ Calving to conception } \\
\hline Conventional $^{3}$ & 114.5 & $105-125$ & 1 & & \\
\hline Selective $^{4}$ & 107.0 & $98-129$ & 0.984 & $0.745-1.300$ & 0.909 \\
\hline
\end{tabular}

${ }^{1} \mathrm{AOR}=$ adjusted odds ratio.

${ }^{2}$ Cure was declared when cows had a clear normal vaginal discharge (VD-0) at the recheck 14 d later.

${ }^{3}$ Conventional treatment strategy: all cows received $500 \mathrm{mg}$ of cephapirin (intrauterine; Metricure, Intervet, the Netherlands).

${ }^{4}$ Selective treatment strategy: cows with $\geq 5$ colonies after $24 \mathrm{~h}$ of incubation in any of the 2 Petrifilm (3M Corp., St. Paul, MN) plates received $500 \mathrm{mg}$ of cephapirin (intrauterine), whereas those with $<5$ colonies remained untreated.

${ }^{5} \mathrm{AHR}=$ adjusted hazard ratio.

for logistic regression. Time intervals (median $\pm 95 \%$ $\mathrm{CI}$ ) and survival function estimates were obtained from Kaplan-Meier survival analysis.

\section{RESULTS}

Overall, 352 cows were enrolled into this study, 178 allocated to the ST group (Argentina, 78 cows; Slovakia, 100 cows) and the remaining 174 to $\mathrm{CT}$ group (Argentina, 74 cows; Slovakia, 100 cows; Figure 1). In the ST group, $57 \%$ of cows had a negative Petrifilm test result, so this strategy allowed a $57 \%$ reduction in the number of antibiotic treatments required.

\section{Cure Rate and Reproductive Performance}

Effects of treatment strategy on cure rate and reproductive performance are shown in Table 1. The percentage of cows cured in the Argentinean herd was $42.3 \%$ and in the Slovakian herd $57.6 \%$. Group (ST vs. CT) had not effect on the odds for cure [adjusted odds ratio $(\mathbf{A O R})=0.939, P=0.800]$ given that the proportion of cured cows was 58 versus $60 \%$ for ST and CT, respectively. Primiparous cows tended to have a higher cure rate than multiparous herd mates (71 vs.
$55 \%, P=0.069)$. The odds for cure decreased with VD $(P<0.001)$ given that the proportion of cured cows was $80 \%(87 / 109)$ vs. $60 \%(89 / 148)$ vs. $33 \%(30 / 92)$ for VD-1, VD-2, and VD-3, respectively. The odds for cure were 0.392 (95\% CI: $0.210-0.733$ ) and 0.122 (95\% CI: $0.060-0.251$ ) for cows with VD-2 and VD3 , respectively. The odds for cure increased by $28.8 \%$ for every increase of $5 \mathrm{~kg} / \mathrm{d}$ in daily milk production above the mean of $35.36 \mathrm{~kg} / \mathrm{d}(\mathrm{AOR}=1.288,95 \% \mathrm{CI}$ : $1.079-1.537, P=0.005$ ).

In the Argentinean herd, CR1AI was $28.8 \%$, and in the Slovakian herd it was $21.3 \%$. Group (ST vs. CT) had no effect on the odds for CR1AI (AOR $=1.117, P=$ $0.555)$ given that the proportion of cows that conceived was 25 versus $24 \%$ for ST and CT, respectively. Group had no effect on the odds for AI80 (46 vs. $50 \%$, AOR = $0.913, P=0.664$ ) or on the odds for P100 (32 vs. $30 \%$, $\mathrm{AOR}=1.142, P=0.603)$. Also, no effect was observed on the odds for NP200 (AOR $=1.113, P=0.724)$ given that the proportion of open cows was 21 versus $19 \%$ for ST and CT cows, respectively. Multiparous cows tended to have lower odds for CR1AI than primiparous cows $(22$ vs. $33 \%, \mathrm{AOR}=0.583,95 \%$ CI: $0.319-1.067$, $P=0.080)$. Multiparous cows had lower odds for P100 than primiparous (29 vs. $38 \%, \mathrm{AOR}=0.495,95 \%$ CI: 
0.247-0.991, $P=0.047)$. The odds for P100 tended to increase by $3.3 \%$ for every increase of $5 \mathrm{~kg} / \mathrm{d}$ in daily milk production above the mean of $35.36 \mathrm{~kg} / \mathrm{d}(\mathrm{AOR}=$ 1.033, 95\% CI: $0.996-1.072, P=0.078)$. The odds for AI80 decreased by $10.6 \%$ for every increase of $0.1 \mathrm{mM}$ of BHB above the mean of $0.65 \mathrm{mM}(\mathrm{AOR}=0.894$, 95\% CI: $0.823-0.971, P=0.008)$. Finally, the odds for NP200 tended to increase $4.7 \%$ for every increase of $0.1 \mathrm{~m} M$ of BHB above the mean of $0.65 \mathrm{~m} M$ (AOR $=$ 1.047, 95\% CI: 0.991-1.106, $P=0.100)$. The remaining predictors had no effect on the odds for any of the evaluated response variables $(P>0.1)$.

Treatment strategy group (ST vs. CT) had no effect on the hazard of AI [adjusted hazard ratio $(\mathbf{A H R})=$ $1.056, P=0.638]$. The median interval from calving to first AI was 81 vs. $80.5 \mathrm{~d}$ for ST and CT, respectively. Also, group had no effect on the hazard of conception $($ AHR $=0.984, P=0.909)$. The median calving to conception interval was 114.5 vs. $107 \mathrm{~d}$ for ST and CT, respectively. Finally, multiparous cows had a lower hazard of conception than primiparous ones $(\mathrm{AHR}=$ $0.608, P=0.022$ ) and took $15 \mathrm{~d}$ longer to get pregnant (117 vs. $102 \mathrm{~d}$, respectively). The remaining predictors had no effect on the hazards of both insemination and conception $(P>0.1)$.

\section{Cytological and Bacteriological Examination}

According to cytological evaluation, the overall proportion of cows with PVD having no evidence of uterine inflammation (false-positive cows to $\mathrm{CE}$ ) was $8.8 \%(31 / 352)$. The distribution of these false-positive cows were 10.3 and $7.3 \%$ for CT and ST, respectively $\left(\chi^{2}=1.081, \mathrm{df}=1, P=0.298\right)$.

In total, $43 \%$ of cows in the ST group had positive Petrifilm test results and received an intrauterine antimicrobial treatment. The outcome of the Petrifilm test was not related to $\operatorname{VD}(P=0.349)$ given that the percentage of positive cows to Petrifilm was 46.9, 46.3, and $40.4 \%$ for those having VD-1, VD-2, and VD-3, respectively. In addition, the outcome of the Petrifilm test was not associated with cytological examination $(P=0.949)$; the percentage of positive cows based on the Petrifilm test was 44.9 and $45.2 \%$ for those having positive $(\geq 5 \%$ PMNL) and negative cytology $(<5 \%$ PMNL), respectively.

From a subsample of 88 cows, samples were not only tested by Petrifilm but also in the laboratory. For these cows, the odds for Trueperella pyogenes increased with VD $(P=0.001)$, given that the odds were $1.339(95 \%$ CI: $0.405-4.426)$ and 8.928 (95\% CI: 2.521-31.615) for cows having VD-2 and VD-3, respectively. The percentage of cows with T. pyogenes was $31.8 \%(7 / 22)$, $38.5 \%(10 / 26)$, and $81.0 \%(25 / 31)$ for cows having
VD-1, VD-2, and VD-3, respectively. The presence of T. pyogenes reduced the odds for cure $(\mathrm{AOR}=0.354$, 95\% CI: $0.133-0.942, P=0.038)$ given that cured cows were $52 \%(22 / 44)$ vs. $76 \%(28 / 37)$ for cows with versus without $T$. pyogenes, respectively.

\section{DISCUSSION}

\section{Cure Rate and Reproductive Performance}

The main hypothesis tested in this study was that the use of the rapid on-farm bacteriological test could help us to select cows with PVD for antibiotic treatment and thus reduce the number of required antibiotic treatments. In agreement with our hypothesis, ST based on the outcome of the Petrifilm test reduced the number of required treatments by approximately $60 \%$ with a similar efficacy as $\mathrm{CT}$, in which all cows received an antibiotic therapy, in terms of clinical cure and reproductive performance. To the best of our knowledge, this study is the first to document this concept. Furthermore, this finding was observed in 2 completely different farming systems, a highly supplemented grazing system (in Argentina) and a freestall system (in Slovakia).

Studies on the on-farm use of Petrifilm to make selective antimicrobial treatment decisions in mastitis therapy have recently found no differences between Petrifilm-based ST and CT in the odds for quarterlevel cure, new intramammary infection, and clinical mastitis (Cameron et al., 2014). They also found no effect in the odds for bacteriological cure and treatment failure and the hazard of clinical cure and culling (Lago et al., 2011a,b). Therefore, the on-farm use of Petrifilm has allowed 21\% (Cameron et al., 2014) and $50 \%$ (Lago et al., 2011a) reductions in the number of required antibiotic treatments without affecting the intended therapeutic outcome. Although these works dealt with mastitis, a completely different disease than $\mathrm{CE}$, the results are in line with ours. Petrifilm-based ST strategy permitted a notable reduction in the use of antibiotics, while still obtaining the same clinical cure and reproductive performance of cows. This finding is relevant because antibiotic use in animal production is blamed for increasing bacterial resistance to antibiotics in humans.

It should be noted that this study was not designed to assess the self-cure rate of cows with $\mathrm{CE}$ or to test the efficacy of a treatment with cephapirin. The implementation of a protocol for selective treatment requires adequate management prerequisites, such as trained personnel, in combination with other routines for which cows need to be restrained. Furthermore, herd-specific economic consideration should be made. Testing all 
cows and reducing the amount of antibiotics can be assumed to be economically superior for herds with a low incidence of bacteriological endometritis compared with herds in which almost all endometritic cows should be treated.

\section{Cytological and Bacteriological Examination}

Surprisingly, the outcome of Petrifilm test (i.e., number of colonies in one or both plates) was related to neither VD nor cytological examination. Unfortunately, we do not have an explanation for this finding. Some studies have demonstrated that cows with abnormal VD may have neither PMNL nor bacteria sampled from the endometrium (Dubuc et al., 2010; Westermann et al., 2010; Hartmann et al., 2016). In the current study, $8.8 \%$ of cows with abnormal VD were negative to cytology (false-positive cows). This figure is a bit lower than previously reported (Westermann et al., 2010). However, evaluation of inflammatory cells by cytobrush technique and manual inspection of VD could reflect different uterine conditions as proposed by Dubuc et al. (2010). Consequently, the lack of agreement between the 2 techniques could play a role in confounding the relationship among Petrifilm, VD, and PMNL count.

A general agreement exists that nonspecific bacterial contamination at parturition could lead to the establishment of uterine infections (Williams et al., 2005). However, severe endometrial lesions are commonly associated with the presence of $T$. pyogenes, which is the most prevalent bacteria in the late postpartum period (Westermann et al., 2010). It is recognized as an important pathogen associated with $\mathrm{CE}$, probably due to synergistic action with anaerobic bacteria (Williams et al., 2005). Our findings that the odds for clinical cure decreased with both VD score and the presence of $T$. pyogenes, and in turn, that the odds for isolating T. pyogenes increased with the VD score and with endometrial PMNL, could be interpreted as being in line with a recent study showing a high prevalence of cytological endometritis in infected cows (Bicalho et al., 2016). The finding also agrees with other research showing that concurrent and subsequent infection of $T$. pyogenes with gram-negative anaerobes such as Fusobacterium necrophorum and Prevotella melaninogenica is associated with higher odds for $\mathrm{CE}$ and with reduced odds for pregnancy (Bonnett et al., 1991; Williams et al., 2005).

\section{CONCLUSIONS}

A treatment strategy based on the use of a quick on-farm bacteriological test (Petrifilm) to select cows with PVD for antibiotic treatment reduced the required number of treatments without decreasing clinical cure or reproductive performance of dairy cows compared with the conventional treatment of all cows having PVD. Thus, Petrifilm is a valuable tool to assist in the prudent use of antimicrobials in the global dairy production system.

\section{ACKNOWLEDGMENTS}

This study was partly financed by the Austrian Agency for Research Collaboration (OeAD) and the Argentinean Ministry of Science, Technology and Productive Innovation (MINCyT) through a cooperation project (no. AU1210) given to M. D. and M. J. G., by a PICT 2013-3260 (MINCYT) given to R.L. de la Sota and M. J. Giuliodori, and by UNLP grants V11/162 and V11/200 to RL de la Sota. Authors acknowledge the MSD Animal Health for their financial support, and the owners and staff of the 2 dairy farms for their great cooperation and hospitality.

\section{REFERENCES}

Arlt, S., W. Padberg, M. Drillich, and W. Heuwieser. 2009. Efficacy of homeopathic remedies as prophylaxis of bovine endometritis. J. Dairy Sci. 92:4945-4953.

Bicalho, M. L., F. S. Lima, V. S. Machado, E. B. Meira Jr., E. K. Ganda, C. Foditsch, R. C. Bicalho, and R. O. Gilbert. 2016. Associations among Trueperella pyogenes, endometritis diagnosis, and pregnancy outcomes in dairy cows. Theriogenology 85:267-274.

Bonnett, B. N., S. W. Martin, V. P. Gannon, R. B. Miller, and W. G. Etherington. 1991. Endometrial biopsy in Holstein-Friesian dairy cows. III. Bacteriological analysis and correlations with histological findings. Can. J. Vet. Res. 55:168-173.

Bredie, W. L., and E. de Boer. 1992. Evaluation of the MPN, Anderson-Baird-Parker, Petrifilm E. coli and Fluorocult ECD method for enumeration of Escherichia coli in foods of animal origin. Int. J. Food Microbiol. 16:197-208.

Brick, T. A., G. M. Schuenemann, S. Bas, J. B. Daniels, C. R. Pinto, D. M. Rings, and P. J. Rajala-Schultz. 2012. Effect of intrauterine dextrose or antibiotic therapy on reproductive performance of lactating dairy cows diagnosed with clinical endometritis. J. Dairy Sci. 95:1894-1905.

Cameron, M., S. L. McKenna, K. A. MacDonald, I. R. Dohoo, J. P. Roy, and G. P. Keefe. 2014. Evaluation of selective dry cow treatment following on-farm culture: Risk of postcalving intramammary infection and clinical mastitis in the subsequent lactation. J. Dairy Sci. 97:270-284.

Denis-Robichaud, J., and J. Dubuc. 2015a. Randomized clinical trial of intrauterine cephapirin infusion in dairy cows for the treatment of purulent vaginal discharge and cytological endometritis. J. Dairy Sci. 98:6856-6864.

Denis-Robichaud, J., and J. Dubuc. 2015b. Determination of optimal diagnostic criteria for purulent vaginal discharge and cytological endometritis in dairy cows. J. Dairy Sci. 98:6848-6855.

Drillich, M., D. Raab, M. Wittke, and W. Heuwieser. 2005. Treatment of chronic endometritis in dairy cows with an intrauterine application of enzymes. A field trial. Theriogenology 63:1811-1823.

Dubuc, J., T. F. Duffield, K. E. Leslie, J. S. Walton, and S. J. LeBlanc. 2010. Definitions and diagnosis of postpartum endometritis in dairy cows. J. Dairy Sci. 93:5225-5233.

Dubuc, J., T. F. Duffield, K. E. Leslie, J. S. Walton, and S. J. Leblanc. 2011. Randomized clinical trial of antibiotic and prostaglan- 
din treatments for uterine health and reproductive performance in dairy cows. J. Dairy Sci. 94:1325-1338.

Edmonson, A. J., I. J. Lean, L. D. Weaver, T. Farver, and G. Webster. 1989. A body condition scoring chart for Holstein dairy cows. J. Dairy Sci. 72:68-78.

Gautam, G., T. Nakao, K. Koike, S. T. Long, M. Yusuf, R. M. Ranasinghe, and A. Hayashi. 2010. Spontaneous recovery or persistence of postpartum endometritis and risk factors for its persistence in Holstein cows. Theriogenology 73:168-179.

Giuliodori, M. J., R. P. Magnasco, D. Becu-Villalobos, I. M. LacauMengido, C. A. Risco, and R. L. de la Sota. 2013. Clinical endometritis in an Argentinean herd of dairy cows: Risk factors and reproductive efficiency. J. Dairy Sci. 96:210-218.

Haimerl, P., W. Heuwieser, and S. Arlt. 2013. Therapy of bovine endometritis with prostaglandin F2alpha: A meta-analysis. J. Dairy Sci. 96:2973-2987.

Hartmann, D., J. Rohkohl, S. Merbach, T. Heilkenbrinker, H. P. Klindworth, H. A. Schoon, and M. Hoedemaker. 2016. Prevalence of cervicitis in dairy cows and its effect on reproduction. Theriogenology 85:247-253.

Hirsbrunner, G., H. W. Burkhardt, and A. Steiner. 2006. Effects of a single administration of prostaglandin F2alpha, or a combination of prostaglandin F2alpha and prostaglandin E2, or placebo on fertility variables in dairy cows $3-5$ weeks post partum, a randomized, double-blind clinical trial. Reprod. Biol. Endocrinol. 4:65.

Kasimanickam, R., T. F. Duffield, R. A. Foster, C. J. Gartley, K. E. Leslie, J. S. Walton, and W. H. Johnson. 2004. Endometrial cytology and ultrasonography for the detection of subclinical endometritis in postpartum dairy cows. Theriogenology 62:9-23.

Kasimanickam, V. R., K. Owen, and R. K. Kasimanickam. 2016. Detection of genes encoding multidrug resistance and biofilm virulence factor in uterine pathogenic bacteria in postpartum dairy cows. Theriogenology 85:173-179.

Kaufmann, T. B., S. Westermann, M. Drillich, J. Plöntzke, and W. Heuwieser. 2010. Systemic antibiotic treatment of clinical endometritis in dairy cows with ceftiofur or two doses of cloprostenol in a 14-d interval. Anim. Reprod. Sci. 121:55-62.

Lago, A., S. M. Godden, R. Bey, P. L. Ruegg, and K. Leslie. 2011a. The selective treatment of clinical mastitis based on on-farm culture results: I. Effects on antibiotic use, milk withholding time, and short-term clinical and bacteriological outcomes. J. Dairy Sci. 94:4441-4456.

Lago, A., S. M. Godden, R. Bey, P. L. Ruegg, and K. Leslie. 2011b. The selective treatment of clinical mastitis based on on-farm culture results: II. Effects on lactation performance, including clinical mastitis recurrence, somatic cell count, milk production, and cow survival. J. Dairy Sci. 94:4457-4467.

LeBlanc, S. J. 2008. Postpartum uterine disease and dairy herd reproductive performance: A review. Vet. J. 176:102-114.

LeBlanc, S. J., T. F. Duffield, K. E. Leslie, K. G. Bateman, G. P. Keefe, J. S. Walton, and W. H. Johnson. 2002. The effect of treatment of clinical endometritis on reproductive performance in dairy cows. J. Dairy Sci. 85:2237-2249.

Machado, V. S., G. Oikonomou, E. K. Ganda, L. Stephens, M. Milhomem, G. L. Freitas, M. Zinicola, J. Pearson, M. Wieland, C. Guard, R. O. Gilbert, and R. C. Bicalho. 2015. The effect of intrauterine infusion of dextrose on clinical endometritis cure rate and reproductive performance of dairy cows. J. Dairy Sci. 98:38493858.
Maquivar, M. G., A. A. Barragan, J. S. Velez, H. Bothe, and G. M. Schuenemann. 2015. Effect of intrauterine dextrose on reproductive performance of lactating dairy cows diagnosed with purulent vaginal discharge under certified organic management. J. Dairy Sci. 98:3876-3886.

McCarron, J. L., G. P. Keefe, S. L. McKenna, I. R. Dohoo, and D. E. Poole. 2009. Laboratory evaluation of 3M Petrifilms and University of Minnesota Bi-plates as potential on-farm tests for clinical mastitis. J. Dairy Sci. 92:2297-2305.

Mejía, M. E., and I. M. Lacau-Mengido. 2005. Endometritis treatment with a PGF2alpha analog does not improve reproductive performance in a large dairy herd in Argentina. Theriogenology 63:1266-1276.

Melcher, Y., I. Prunner, and M. Drillich. 2014. Degree of variation and reproducibility of different methods for the diagnosis of subclinical endometritis. Theriogenology 82:57-63.

NRC. 2001. Nutrient Requirements of Dairy Cattle. 7th rev. ed. Natl. Acad. Press, Washington, DC.

Pleticha, S., M. Drillich, and W. Heuwieser. 2009. Evaluation of the Metricheck device and the gloved hand for the diagnosis of clinical endometritis in dairy cows. J. Dairy Sci. 92:5429-5435.

Plöntzke, J., L. V. Madoz, R. L. De la Sota, W. Heuwieser, and M. Drillich. 2011. Prevalence of clinical endometritis and its impact on reproductive performance in grazing dairy cattle in Argentina. Reprod. Domest. Anim. 46:520-526.

Prunner, I., K. Wagener, H. Pothmann, M. Ehling-Schulz, and M. Drillich. 2014. Risk factors for uterine diseases on small- and medium-sized dairy farms determined by clinical, bacteriological, and cytological examinations. Theriogenology 82:857-865.

Runciman, D. J., G. A. Anderson, and J. Malmo. 2009. Comparison of two methods of detecting purulent vaginal discharge in postpartum dairy cows and effect of intrauterine cephapirin on reproductive performance. Aust. Vet. J. 87:369-378.

Santos, T. M., L. S. Caixeta, V. S. Machado, A. K. Rauf, R. O. Gilbert, and R. C. Bicalho. 2010. Antimicrobial resistance and presence of virulence factor genes in Arcanobacterium pyogenes isolated from the uterus of postpartum dairy cows. Vet. Microbiol. 145:84-89.

Schraft, H., and L. A. Watterworth. 2005. Enumeration of heterotrophs, fecal coliforms and Escherichia coli in water: Comparison of 3M Petrifilm plates with standard plating procedures. J. Microbiol. Methods 60:335-342.

Sheldon, I. M., G. S. Lewis, S. LeBlanc, and R. O. Gilbert. 2006. Defining postpartum uterine disease in cattle. Theriogenology 65:1516-1530.

Trevisi, E., A. Zecconi, S. Cogrossi, E. Razzuoli, P. Grossi, and M. Amadori. 2014. Strategies for reduced antibiotic usage in dairy cattle farms. Res. Vet. Sci. 96:229-233.

Westermann, S., M. Drillich, T. B. Kaufmann, L. V. Madoz, and W. Heuwieser. 2010. A clinical approach to determine false positive findings of clinical endometritis by vaginoscopy by the use of uterine bacteriology and cytology in dairy cows. Theriogenology 74:1248-1255.

Williams, E. J., D. P. Fischer, D. U. Pfeiffer, G. C. England, D. E. Noakes, H. Dobson, and I. M. Sheldon. 2005. Clinical evaluation of postpartum vaginal mucus reflects uterine bacterial infection and the immune response in cattle. Theriogenology 63:102-117. 